\title{
JAIME II Y LOS JUDÍOS EN LA CORONA DE ARAGÓN
}

\author{
Yom TOV ASSIS \\ Universidad Hebrea de Jerusalén
}

\section{EL REY Y LOS JUDÍOS}

La posición de los judíos en la Corona de Aragón no permaneció constante en los siglos XIII-XIV porque la política de los monarcas con respecto a ellos no fue totalmente consistente. Sin embargo, hay ciertos principios que conservaron su validez hasta las matanzas de 1391. Uno de gran importancia es el que afirma que «judei sunt domini regis»'. Siempre que aparece este principio está relacionado con la propiedad y los bienes y así vemos que los judíos son mencionados como «cofres del senyor Rey», "peculium et thesaurus noster», «tresor e case nostra propia»y «nostrae camerae servi speciales" ${ }^{2}$. Al ser propiedad del rey, los judíos gozaban de la protección del monarca ${ }^{3}$. Este es un principio fundamental que todos los reyes-condes mantuvieron desde la época de Ramón Berenguer IV que unió Aragón y Cataluña en 1137. Sin él, la existencia de los judíos en la Corona de Aragón habría corrido peligro. Aunque con el transcurso del tiempo las nuevas condiciones creadas acarrearon cambios en la política judía de la Corona y, por consiguiente, en la posición de los judíos, el

1 T. MIERES, Apparatus super constitutionibus curiarum generalium Cathaloniae, I, Barcelona, 1621, p. 62b; J. BERGUA CAMÓN, “Fueros de Aragón de 1265 a 1381 ", Anuario de Derecho Aragonés, V (1949-50), p. 455.

2 J. COROLEU, Documents historichs catalans del sigle XI, Barcelona, 1889, p. 61; F. DE BOFARULL Y SANS, Los judíos en el territorio de Barcelona (siglos $X$ al XIII), Reinado de Jaime I, 1213-1276, Barcelona, 1910, p. 37.

3 P. CABARTE, Fueros y observaciones del reyno de Aragón, Saragossa, 1624, p. 11b; ACA [=Archivo de la Corona de Aragón], Reg. 43, fo. 30v [=J. RÉGNÉ, History of the Jews in Aragón, ed. Y. Assis, Jerusalem, 1978, no. 1206 (=Régné)]. 
monarca nunca renunció a reivindicar su calidad de propietario de los judíos, lo que contribuyó a la relativa estabilidad de que gozaron los judíos de la Corona hasta 1391.

Desde el punto de vista del rey, los judíos suponían una importante fuente de ingresos. Por eso, en períodos en que las arcas reales estaban casi vacías, normalmente la posición de los judíos se fortaleció. Para el rey, estos últimos suponían un elemento valioso que estaba interesado en conservar y, mejor aún, en aumentar. La famosa invitación que hizo Jaime $\mathrm{I}$ a los judíos para que se radicaran en los territorios de la Corona de Aragón y especialmente en el Reino de Valencia, constituye una evidencia clara del valor que otorgaba a sus súbditos judíos ${ }^{4}$. El aliento a la inmigración de judíos a las tierras de la Corona de Aragón, siguió siendo un elemento importante de la política de sus sucesores. Pedro III prosiguió la política de su padre ${ }^{5}$ y Jaime II, además de alentar la inmigración de judíos, prohibió su emigración ${ }^{6}$. El objetivo de prohibir la emigración de judíos era prevenir pérdidas económicas y, por lo tanto, constituía otro aspecto de la misma política de los reyes-condes ${ }^{7}$. Cada judío adicional suponía una ganancia para el tesoro. Todo ataque contra ellos o sus propiedades, conllevaba una reacción inmediata del rey que no quería ver disminuidos sus ingresos. La multa que tenía que pagar el que asesinara o matara accidentalmente a un judío, muestra el valor que este último tenía a ojos del rey y no importa en este contexto si dicha imposición estaba concebida para compensar al rey o para prevenir ataques posteriores ${ }^{8}$. En resumen, el rey tenía para con los judíos la actitud que tiene un propietario con respecto a lo que le pertenece. Cuando el arzobispo de Tarragona intentó impedir en 1300 que los oficiales reales recaudaran impuestos de los judíos locales actuando con ello de acuerdo a la decisión de las Corts de Barcelona, Jaime II expresó su sorpresa ante esta interferencia y declaró que todos los judíos de Cataluña eran propiedad privada suya y que, por lo tanto, tenía derecho a imponerles las cargas fiscales que quisiera ${ }^{9}$. De más está decir que los judíos no podían someterse a ninguna otra jurisdicción sin consentimiento previo del rey ${ }^{10}$.

Durante este período, la vigilancia que el rey ejercía sobre los judíos por considerarlos propiedad suya o parte de su tesoro, redundó en ventaja de ellos. En 1290, Alfonso III detuvo un proceso iniciado por el Conde de Ampurias contra los judíos de

4 J. VILLANUEVA, Viage literario a las iglesias de España, XII, Madrid, 18xx, pp. 327-8; A.P.V. MOREL-FATIO, "Notes et documents pour servir à l'histoire des Juifs des Baléares sous la domination aragonaise du XIlle au Xve siècle», Revue des Etudes Juives, IV (1882), p. 32, no. 1; ACA, Reg. 16, fo. 199 [=Régné 443].

5 Sobre la inmigración de judíos del África del norte, véase ACA, Reg. 40, fo. 80v [=Régné 691 =J.E. MARTÍNEZ FERRANDO, Catálogo de la documentación relativa al antiguo Reino de Valencia, Madrid, 1943, II, no. 332; de judíos de Castilla, véase ACA, Reg. 60, fo. 56v [=Régné 1032].

6 Y. ASSIS, «Juifs de France réfugiés en Aragón (XIIle-XIVe siècles) », Revue des Etudes Juives, CXLII (1983), pp. 294-299; ACA, Reg. 256, fo. 1v [=Régné 2674]; Reg. 195, fo. 120 [=Régné 2675].

7 ACA, Reg. 10, fo. 37 [=Régné 94]; Reg. 56, fo. 59v [=Régné 1337].

8 ACA, Reg. 204, fo. [=Régné 2868]; Reg. 194, fo. 266 [=Régné 2623]; Reg. 197, fo. 19v [=Régné $2720=$ F. BAER, Die Juden im christlichen Spanien, I, Berlin, 1929, no. 142].

9 ACA, Reg. 257, fo. 44v [=Régné 2725].

10 ACA, Reg. 204, fo. 73 [=Régné 2874]. 
sus dominios, argumentando de que sólo el rey tenía autoridad para investigar sus acciones y juzgarlos. Además, el monarca sostenía que los judíos pertenecían a la Corona y que, por consiguiente, cualquier daño que sufrieran atentaría contra sus intereses ${ }^{11}$. La respuesta que Jaime II dio en 1294 a la reina de Castilla que le había pedido que nombrara a Salamón Constantín jutge o rap (juez o rabino) de los judíos de Aragón, es una buena muestra de las ventajas que los judíos podían derivar del hecho de ser propiedad del rey. Este último, que sabía que los judíos se oponían al nombramiento, rechazó la petición de la reina diciendo «... non devedes querer que por un judio perdamos los otros» ${ }^{12}$. De hecho, hizo cuanto pudo por no perder su jurisdicción sobre sus súbditos judíos y actuó con gran diligencia para defenderlos y protegerlos en momentos de peligro. Tomó medidas y ofreció medios para garantizar su bienestar y los estimuló a que se asentaran en sus dominios ${ }^{13}$.

Esta actitud del rey estaba motivada por consideraciones económicas y no tenía nada que ver con sus sentimientos respecto a los judíos. Los verdaderos sentimientos de Jaime II por sus súbditos judíos quedan expresados en una carta que envió a su hija Constanza con ocasión del nacimiento del hijo de esta última en 1321. En ella, el rey la advierte que, en lo que respecta a la educación del recién nacido, no siga el consejo de los judíos como había hecho previamente la infanta en otros terrenos ${ }^{14}$. La carta nos muestra, por una parte, la estrecha relación de ciertos judíos con los miembros de la familia real y, por otra, las reservas y prejuicios personales del rey hacia los judíos tal como los expresaba en su correspondencia privada. Los reyes-condes supieron acallar sus sentimientos personales y tratar a los judíos según los beneficios que el reino pudiera derivar de ellos. La posición de los judíos estaba determinada, en muy buena medida, por los beneficios económicos, reales o imaginarios, que los reyes esperaban poder obtener de ellos.

\section{LOS JUDIOOS Y LA RECONQUISTA}

La posición de los judíos durante los reinados de Jaime I y Pedro III parecía estable y segura; su contribución a la Corona estaba entonces en su momento culminante. Con Jaime I, los judíos fueron considerados un elemento apropiado para colonizar Mallorca y Valencia, zonas que acababan de ser conquistadas y cuya repoblación era vital para el rey desde los puntos de vista demográfico y económico así como por motivos de seguridad. Tras la conquista, especialmente en Mallorca, se produjo una emigración sustancial de musulmanes, población cuya lealtad al monarca era, por otra parte, cuestionable. Los judíos eran candidatos ideales para la colonización y, desde

11 ACA, Reg. 81, fos. 87, 236 [=Régné 2107, 2265].

12 ACA, Reg. 252, fo. 50 [=Régné 2551 =BAER, Die Juden, doc. 136.

13 ACA, Reg. 198, fo. 228 [=Régné 2747]; Reg. 212, fo. 60v [=Régné 3029]; Reg. 216, fo. $24 \mathrm{~V}$ [=Régné 3089]; Reg. fos. 258-9 [=Régné 3057]; Reg. 214, fos. 102v-103 [=Régné 3069].

14 ACA, Reg. 246, fo. 310 [=A. GIMÉNEZ SOLER, D. Juan Manuel: biografía y estudio crítico, Zaragoza, 1932, apéndice, no. 374 =J.E. MARTíNEZ FERRANDO, Jaime Il, su vida familiar, ll, Barcelona, 1948, doc. 366]. 
el punto de vista del rey, preferibles incluso a los cristianos procedentes de la nobleza catalana o aragonesa que podían resultar rivales políticos. La radicación de judíos en esas zonas no era sólo importante para aumentar la proporción de no musulmanes en los territorios conquistados, sino también para colonizar tierras que los fugitivos habían abandonado o que habían sido confiscadas a manos enemigas. Estimular a que un sector de la población sirviera de elemento colonizador tomando el lugar de los musulmanes a los que se permitió emigrar a Granada y al norte de África, constituyó una de las piedras angulares de la política de la Corona en las nuevas posesiones ${ }^{15}$. La relativa tolerancia que el monarca aragonés había mostrado con los musulmanes, llegó a su fin con las rebeliones de estos últimos ${ }^{16}$ y el rey incrementó las presiones para que los musulmanes emigraran al norte de África ${ }^{17}$ en la misma medida en que estimuló a los judíos a que trasladaran sus hogares a la región y los reemplazaran. La contribución de los judios a la economía y a la colonización del sur fue sustancial. Lo que es más, Jaime I encontró en Mallorca y en Valencia una pequeña población judía local ${ }^{18}$ cuya afortunada integración fortaleció la posición de los judíos recién llegados ${ }^{19}$.

\section{JUDÍOS AL SERVICIO DEL REY}

Durante el reinado de Pedro III, los esfuerzos y recursos de la política exterior se dirigieron a la expansión por el Mediterráneo incluyendo Sicilia, Malta, Kerkennah, Pantelleria y Jerba. Este cambio puso casi un punto final al cometido que los judíos habian desempeñado en el programa de colonización aunque no en el que jugaban en el terreno económico. La Reconquista catalano-aragonesa quedó interrumpida cuando Castilla conquistó el Reino de Murcia creando un tapón entre la Corona de Aragón y la Andalucía musulmana. Los intereses catalanes se dirigieron allende el mar y habría sido de esperar un cierto deterioro en la posición de los judíos pero, en esa época, estos últimos empezaron a jugar un papel alternativo muy importante para la política del rey. Paralelamente a su vasto programa de expansión territorial y económica, Pedro III tenía el proyecto de establecer un sistema político centralizado, independiente de la nobleza. Con este fin, trató de formar un servicio civil basado en el

15 J. VICENS VIVES, Historia social y económica de España y América, II, Barcelona, 1957-9, pp. 39, 50, 61; J.E. MARTÍNEZ FERRANDO, «Estado actual de los estudios sobre la repoblación en los territorios de la Corona de Aragón (siglos XII-XIV)", VII Congreso de Historia de la Corona de Aragón, I (1962), p. 153; Ch. DUFOURCQ, L'Espagne catalane et le Maghrib, Paris, 1966, p. 154 y en general véase R.I. BURNS, Medieval Colonialism: Postcrusade Exploitation of Islamic Valencia, Princeton, 1975.

16 J. ZURITA Y CASTRO, Anales de la Corona de Aragón, I, Zaragoza, 1610, fo. 167v.

17 ACA, Reg. 9, fo. 28; Reg. 10, fo. 62v; DUFOURCQ, L'Espagne catalane, p. 187.

18 La destrucción de las comunidades judías de al-Andalus fue casi total como consecuencia de la invasión de los Almohades en 1148. Una gran parte de los judíos andaluces se trasladaron al norte, a los reinos hispánicos donde continuaban su tradición y cultura judeo-árabe. Véase Y. ASSIS, “The Judeo-Arabic Tradition in Christian Spain", The Jews of Medieval Islam; Community, Society, \& Identity, ed. D. Frank, Leiden, New York, Köln, 1995, pp. 111-124.

19 VICENS VIVES, Historia social, II, p. 56. 
empleo de oficiales judíos y estuvo a punto de lograrlo ${ }^{20}$. Su elección no es de extrañar. En general, los judíos demostraron poseer muy buenas aptitudes para la administración. Eran totalmente leales al rey y dependían por completo de la Corona. El intento falló cuando la nobleza se negó a enviar tropas para rechazar la invasión francesa de 1283 a no ser que el rey despidiera a sus oficiales judíos. Los despidos echaron abajo el proyecto que, de haber tenido éxito, habría privado a la nobleza de todo poder y posición políticos ${ }^{21}$.

En 1283, Pedro III prometió a los nobles de Aragón, Valencia y Cataluña que, a partir de entonces, no nombraría baile a ningún judío ${ }^{22}$. En diciembre de 1283 , al confirmarse los fueros, reiteró su promesa a los burgueses ciudadanos de Valencia asegurando que ningún judío ejercería la función de baile «nec officium publicum teneat unde super christianum habeat jurisdictionem" ${ }^{23}$. En enero de 1284, se informó a los nobles catalanes de la exclusión final y definitiva de los judíos de todos los cargos públicos ${ }^{24}$. Estas promesas, de hecho, suponían la puesta en práctica de una prohibición que databa de 1228 y prohibía a los judíos ocupar cualquier cargo que les diera competencia judicial sobre cristianos ${ }^{25}$.

No hay que subestimar las serias consecuencias que tuvo para los judíos el que el rey se sometiera a las demandas de la nobleza. Esto último constituyó un cambio decisivo en la historia de los judíos de la Corona de Aragón, el comienzo de su decadencia y la primera etapa de un proceso que culminaría en matanzas, conversiones forzadas y destrucción. Pero la opinión de que la Corona ya no necesitó de los judíos una vez que el proyecto del monarca hubo fracasado, resulta totalmente insostenible ${ }^{26}$. Tanto el propio Pedro III como su sucesor Alfonso III, siguieron utilizando los

20 L. KLÜPFEL, "El règim de la confederació catalano-aragonesa a finals del segle XIII», Revista Jurídica de Catalunya XXXV (1929), pp. 34-40, 195-226, 289-327; XXXVI (1930), pp. 18-37, 97-135, 298-331; J.L. SHNEIDMAN, "The Jews in the Royal Administration of XIIIth Century Aragón», Historia Judaica XXI (1959), pp. 37-52; D. ROMANO, Judios al servicio de Pedro el Grande de Aragón (12761285), Barcelona, 1983; Y. ASSIS, "Diplomáticos judíos de la Corona de Aragón en países islámicos", Sefunot III (18) (1985), pp. 11-34 (en hebreo).

21 SHNEIDMAN, «The Jews in the Royal Administration"; D. ROMANO, «Los funcionarios judios de Pedro el Grande de Aragón", Boletín de Real Academia de Buenas Letras de Barcelona XIX (106970), p. 31; KLÜPFEL, «El règim», XXXV, p. 313.

22 Sobre Aragón, véase J. BERGUA CAMÓN, "Fueros de Aragón de 1265 a 1381 ", Anuario de Derecho Aragonés V (1949-50), p. 455; sobre Valencia, véase ACA, Reg. 62, fo. 18; Reg. 47, fo. 53; sobre Cataluña, véase F. SOLDEVILA, Historia de Catalunya, I, Barcelona, 1962, pp. $362 \mathrm{ff}$.

23 Colección de documentos inéditos del Archivo de la Corona de Aragón, «Procesos de las antiguas Cortes", VI, p. 166.

24 Constitucions y altres drets de Cathalunya, II, Barcelona, 1704 (reedición 1909), p. 49; D. ROMANO, "Los funcionarios judíos de Pedro el Grande de Aragón", Boletín de la Real Academia de Buenas Letras de Barcelona [=BABLB] XIX (1969-70), p. 31.

25 «... ut judei officia judicandi vel puniendi exercere non presumant». Archivo Municipal de Barcelona, Llibre vert, I, fo. 79 .

26 Véase J.L. SHNEIDMAN, «Jews as Royal Bailiffs in XIIIth Century Aragón», Historia Judaica XIX (1957), p. 66. 
servicios de oficiales judíos en los mismos terrenos que antes aunque sin darles el título de baile. En este periodo de transición, los judíos continuaron empleados en la corte hasta que Jaime II cambió su política judía. Lo que es más, los judíos, que seguían siendo propiedad del rey, constituían todavía un elemento valioso. Quedaban varios campos - por ejemplo la medicina y la ciencia así como las finanzas y el sistema tributario- en los que los judíos descollaron hasta el punto de que ni siquiera la nobleza, la Iglesia o la burguesía pudieron prescindir de ellos. Por lo tanto, no es de sorprender que, en momentos en que monarcas de otros países cristianos estaban expulsando a los judíos de sus tierras, los reyes aragoneses recibieran a los refugiados con los brazos abiertos ${ }^{27}$. A la caída de los cortesanos y oficiales judíos de Pedro III no le siguió una decadencia económica de las comunidades judías ni la ausencia de oficiales judíos de la corte anuló la importancia de las comunidades, ya fuera ésta real o imaginaria ${ }^{28}$. El propio rey expresó en varias ocasiones la estima en que los tenía.

\section{LOS OFICIALES JUDÍOS DESPUÉS DE 1283}

En el periodo de transición que va de 1283 a 1291, varios judíos cumplieron misiones políticas y económicas. Entre ellos encontramos a Mossé Ravayaa ${ }^{29}$, Muça de Portella ${ }^{30}$, sus hermanos Abraham, Salamón e Ismael y a Aharón ibn Yahia ${ }^{31}$. En esos años, sobresale particularmente la labor de diplomáticos judíos al servicio del rey-conde. Las misiones de estos diplomáticos a tierras musulmanas fueron muy apreciadas. Se les confiaron por su conocimiento del árabe, porque eran expertos en asuntos de los países islámicos en general y porque estaban al corriente de la situación en los reinos musulmanes de España y de África del Norte. Mencionemos entre otros a Abraham ibn Gallel, enviado de Pedro III a Granada en 1280 y $1284^{32}$ que también cumplió misiones diplomáticas para Alfonso Ill en Marruecos, Tlemecén y Granada ${ }^{33}$; a Vidal de Porta, enviado a Marruecos en $1286^{34}$ y a Samuel Alfaquim, que llevó a cabo misiones diplomáticas en Marruecos y Granada en varias ocasiones ${ }^{35}$. Estos embajado-

27 Y. ASSIS, «Juifs de France réfugiés en Aragón (XIIlè-XIVè siècles)», Revue des Etudes Juives CXLII (1983), pp. 209-227.

28 Y. ASSIS, "Los judíos de la Corona de Aragón y sus dominios", El Legado de Sefarad, ed. H. Beinart, I, Jerusalem, 1992, pp. 95-100.

29 ROMANO, "Los funcionarios judíos», pp. 32-33.

30 ROMANO, «Los funcionarios judíos», pp. 33-35; ACA, Reg. 71, fo. 149v [=Régné 1129]; Reg. 58 , fo. 58 , fo. [=Régné 1389 ].

31 ROMANO, "Los funcionarios judíos», pp. 35-36; ACA, Reg. 43, fo. 90v [=Régné 1248]; Reg. 57, fos. 144, 188 [=Régné 1397, 1442]; Reg. 57, fo. 222v [=Régné 1457 =MARTíNEZ FERRANDO, Catálogo, II, no. 2298].

32 ACA, Reg. 48, fo. 83v [=A. GIMÉNEZ SOLER, "La Corona de Aragón y Granada», BABLB III (1905-6), pp. 113-114 =Régné 810 \& doc. XII =MARTíNEZ FERRANDO, Catálogo, II, no. 1107].

33 ACA, Reg. 64, fo. [=Régné 1701]; DUFOURCQ, L'Espagne catalane, pp. 211-213, 217.

34 DUFOURCQ, L'Espagne catalane, p. 213.

35 ACA, Reg. 47, fo. 41; DUFOURCQ, L'Espagne catalane, pp. 225-227. 
res tuvieron una influencia en la formación de la política exterior de la Corona con respecto a sus vecinos musulmanes ${ }^{36}$.

Tanto el rey como su familia, siguieron utilizando los servicios de médicos judíos incluso después de 1283. Samuel ibn Menasse, que fue nombrado médico de Pedro III en 1279, continuó en ese cargo hasta octubre de $1285^{37}$. Bondavid Bonsenyor fue médico del infante a partir de $1284^{38}$. En 1287 , el médico del infante era un judío llamado Josef ${ }^{39}$. Samuel ${ }^{40}$ y Josef de Orta (o Huert) ${ }^{41}$, fueron médicos de Alfonso III.

A finales del siglo 13, tomó cuerpo una nueva política judía. Incluía elementos antiguos y principios nuevos y quedaría en vigor hasta 1391. En general, se mantenían los privilegios existentes pero el cortesano judío no representaba la posición de los judíos en la Corona de Aragón. El cortesano no desapareció totalmente, pero quedó al margen. A partir de entonces fue la aljama la responsable del destino de sus miembros. Esto produjo un cambio enorme en la vida judía en los territorios de la Corona de Aragón. La autoridad de la aljama se hizo más extensiva y por primera vez judíos de las clases inferiores tomaron parte en su administración. Paradójicamente el declive de los cortesanos judíos que habían determinado el carácter del judaísmo catalanoaragonés-valenciano hasta 1283, aumentó el prestigio de la aljama. Los cortesanos judíos que habían sido hasta entonces los dirigentes naturales de la aljama, recibieron un duro golpe y cedieron el lugar a una nueva administración que incluía representantes de las clases inferiores. Esto provocó cambios de largo alcance en la dirección de la aljama como protectora de sus miembros. Este reforzamiento venía a compensar la pérdida del apoyo que previamente le habían proporcionado sus miembros eminentes, quienes la habían representado con éxito y de manera honorable en su calidad de representantes sin nombramiento formal. Simultáneamente, al subir los estratos inferiores - que contribuyeron también a transformar la aljama en el eje de la actividad judía a finales del siglo 13 y principios del 14-judíos capaces y ambiciosos, a quienes a partir de 1283 había quedado vedado el acceso al poder político, volcaron ahora su atención a los asuntos comunitarios. De esa forma, en la vida de los judíos de la Corona de Aragón tuvieron lugar cambios importantes que eran consecuencia de un proceso que se había iniciado en 1283 y que terminó durante el reinado de Jaime II.

36 ASSIS, «Diplomáticos judíos", pp. 11-34.

37 ACA, Reg. 43, fo. 129v [=D. ROMANO, "Los hermanos Abenmenassé al servicio de Pedro el Grande de Aragón", Homenaje a Millás Vallicrosa, II, Barcelona, 1956, doc. I]; Reg. 46, fo. 178v [=Régné 1117].

38 ROMANO, "Los hermanos Abenmenassé», p. 36; ACA, Reg. 62, fo. 109.

39 ACA, Reg. 71, fo. [=Régné 1747].

40 ACA, Reg. 70 , fo. $190 \mathrm{v}$ [=Régné 1774].

41 ACA, Reg. 75, fos. 28v, $33 v$ [=Régné 1780, 180405]; Reg. 74, fo. 43 [=Régné 1843-4]. Sobre médicos judíos en la Corona de Aragón, véase Y. ASSIS, «Jewish Physicians and Medicine in Medieval Spain", Medicine and Medical Ethics in Medieval and Early Modern Spain, an Intercultural Approach, ed. S.S. Kottek and L. García-Ballester, Jerusalem, 1996, pp. 33-49. 


\section{JAIME II Y LA ALJAMA JUDÍA}

El rey Jaime Il reforzó la aljama como alternativa a los cortesanos porque era consciente de la necesidad de garantizar la seguridad y la existencia misma de los judíos que seguían constituyendo una fuente de ingresos nada despreciable para el tesoro real. Uno de las primeras medidas que tomó el rey a su retorno de Sicilia fue la de iniciar la confirmación de los privilegios de las aljamas, proceso que se prolongaría a lo largo de todo su reinado ${ }^{42}$. Esto se hizo, a petición de las aljamas, por medio de representantes destacados ante la corte y costó a los judíos fuertes sumas de dine$\mathrm{ro}^{43}$. Los privilegios que otorgó Jaime II demuestran el interés del rey por reforzar la autoridad de la aljama. En general, su política consistía en soslayar cualquier prejuicio a la posición de la aljamas y facilitar la existencia de una vida comunitaria acorde con las necesidades de la sociedad judía ${ }^{44}$.

En Elche y Orihuela, al sur de Valencia, territorio conquistado por Jaime II, se volvieron a tomar medidas para renovar el asentamiento de judíos a pequeña escala y el monarca adoptó respecto a ellos la misma política colonizadora que se había seguido en el pasado ${ }^{45}$. También los infantes estimularon a los judíos a radicarse en sus tierras ofreciéndoles amplia autonomía, el derecho para observar los preceptos judíos y condiciones económicas favorables ${ }^{46}$. Esta política judía, que se seguiría hasta 1391, se basaba ante todo en consideraciones económicas. En 1306, cuando las comunidades judías de Europa occidental estaban en proceso de decadencia y extinción, los judíos de la Península Ibérica todavía gozaban del favor de los reyes. De hecho, Jaime II permitió a los exiliados judíos de Francia que se radicaran en su reino y sus motivos eran claramente económicos ${ }^{47}$. El rey seguía contando con el capital judío para sufragar sus empresas. Pidió prestado dinero a judíos para la campaña de Almería en 1309 y recibió de ellos enormes cantidades para adquirir Urgel en 1322. Durante las preparaciones para la campaña de Cerdeña, el rey pidió a los judíos de su reino que contribuyeran con la suma de 500.000 sueldos, que era casi el equivalente de la contribución total de Cataluña entera. Lo que es más, a todos los que participaron en la guerra contra Cerdeña se les concedió una moratoria en las deudas que tenían contraídas con los judíos ${ }^{48}$.

42 ACA, Reg. 191, fos. 27v [=Régné 2392, 2401]; Reg. 192, fos. 54v, 74 [=Régné 2422, 2429]; Reg. 100, fo. 187 [=BAER, Die Juden, doc. 137 = Régné 2629]; Reg. 197, fo. 19v [=BAER, Die Juden, doc. 142 =Régné 2720].

43 ACA, Reg. 192, fo. 74 [=Régné 2429].

44 ACA, Reg. 194, fo. 266 [=Régné 2623]; Reg. 196, fo. 151v [=Régné 2688]; Reg. 212, fo. 145 [=Régné 3037]; Reg. 226, fo. 137v [=Régné 3328].

45 ACA, Reg. 212, fo. 145 [=Régné 3037].

46 ACA, Reg. 383, fos. 40-42 [=BAER, Die Juden, doc. 175].

47 ASSIS, “Juifs de France», pp. 285-322.

48 Sobre Almería véase A. GIMÉNEZ SOLER, El sitio de Almería en 1309, Barcelona, 1904, pp. 90-92; sobre Sardinia, véase A. ARRIBAS I PALA, La conquista de Cerdeña por Jaime I/ de Aragón, Barcelona, 1952, pp. 183-184; J.N. HILLGARTH, The Spanish Kingdoms 1250-1416, Oxford, 1976, p. 240; Y. ASSIS, «Jewish Capital and the Conquest of Sardinia by the Catalans», Italia IX (1990), pp. 7-18. 
Jaime II mantuvo una estrecha relación con eruditos y médicos judíos y estos últimos lo trataron a él y a su familia. Se interesó también por las obras científicas y literarias de los judíos y les encargó la redacción de libros en estos campos del saber. Durante la persecución de los pastoureaux en 1320, tomó medidas para evitar que se extendieran contra los judíos tumultos y ataques como la matanza que tuvo lugar en la comunidad de Montclús ${ }^{49}$.

Jaime II se involucró más en la vida interna de la comunidad y sus actividades cotidianas, que ninguno de sus predecesores. A pesar de ello, se cuidó de no recortar demasiado la autonomía judía. Convenía a sus intereses dejar en manos de la comunidad judía el suficiente poder como para que pudiera cumplir las tareas y obligaciones que tenía contraídas con la Corona. La autonomía judía siguió siendo una condición natural dentro de la estructura de la sociedad medieval y los judíos de los territorios de la Corona de Aragón, con sus normas, leyes, costumbres, idiomas e instituciones distintas de las del resto de la sociedad, estaban todavía más separados de esta última que en ninguna otra parte del mundo medieval. Por eso, cuando el rey sostenía que tenía derecho exclusivo sobre los judíos, su afirmación era más cierta en la Corona de Aragón que en ningún otro país de la Europa cristiana. Jaime II se opuso a los repetidos intentos de la Iglesia y de la Inquisición de extender sus respectivas jurisdicciones a los judíos, argumentando que «cum non sint de fide seu lege catolica et si in aliquo excesserint contra legem, sint per nos puniendi $\gg{ }^{50}$. En las circunstancias que acabamos de mencionar, el que Jaime II se inmiscuyera en la autonomía judía apoyando simultáneamente el poder de la comunidad, no resulta tan contradictorio como pudiera parecer a simple vista.

Jaime II jugó un papel muy importante en los cambios que se produjeron en el sistema de gobierno y el liderazgo de la comunidad judía. Interfirió en numerosas ocasiones tanto en el nombramiento como en el despido de dirigentes y funcionarios judíos $^{51}$. Al igual que sus predecesores, Jaime II recompensó a algunos de sus favoritos judíos a expensas de la comunidad, sin tomar en consideración los derechos autonómicos de esta última. El hecho de que diera su apoyo a ciertos judíos individuales que estaban enfrentados con la comunidad, tuvo asimismo un efecto negativo en la autonomía judía ${ }^{52}$. La inmiscusión del rey en los asuntos de la comunidad, solía

49 J. MIRETY SANS, “Le massacre des Juifs de Montclús», Revue des Etudes Juives LIII (1907), pp. 255-266.

50 ACA, Reg. 92, fo. 144 [=BAER, Die Juden, doc. 133]; cf. S. GRAYZEL, «Popes, Jews and Inquisition", A.I. KATSCH and L. NEMOY (ed.), Essays on the Occasion of the Senetieth Anniversary of the Dropsie University (1909-1979), Philadelphia, 1979, pp. 181-182.

51 ACA, Cartas Reales [=CR], Jaime II, Caja 134, no. 198 [=M CINTA MAÑE (ed.), The Jews in the Crown of Aragón, Regesta of the Cartas Reales in the Archivo de la Corona de Aragón, Part I: 10661327, Sources for the History of the Jews in Spain 4, Yom Tov Assis (ed.), no. 408]; Caja 133, no. 343.

52 ACA, Reg. CR, Jaime II, Caja 49, no. 6040 [=CINTA, The Jews in the Crown of Aragón, no. 204]; Caja 133, no. 116 [=CINTA, The Jews in the Crown of Aragón, no. 337]; Caja 43, no. 5331 [=CINTA, The Jews in the Crown of Aragón, no. 188]; Caja 14, no. 1828 [=CINTA, The Jews in the Crown of Aragón, no. 99]; Caja 133, no. 23 [=CINTA, The Jews in the Crown of Aragón, no. 246]; Caja 134, nos. 196, 207 [=CINTA, The Jews in the Crown of Aragón, nos, 407, 416]. 
tener relación con los impuestos. Su intervención no pudo por menos de restringir la autonomía de la comunidad, cuyo prestigio sufrió también del apoyo que el rey prestaba a ciertos contribuyentes individuales a su costa. En ocasiones, la comunidad sufrió severas humillaciones y las medidas que contra ella tomó el monarca, como cerrar las puertas de la judería o hacer detener a sus dirigentes, supusieron un duro golpe a sus derechos ${ }^{53}$. Las excepciones y reducciones fiscales que el monarca concedió a ciertos judíos que normalmente pertenecían a las capas adineradas, no sólo constituían una carga económica, sino también una violación de la jurisdicción comunitaria ${ }^{54}$. La medida de Jaime Il que tuvo un mayor impacto sobre la vida judía fue, sin embargo, la reforma que cambió el régimen interno de las aljamas.

\section{LA LUCHA DE LAS CLASES INFERIORES POR EL PODER}

El malestar social en el seno de las comunidades judías, que había comenzado en Aragón ya durante el reinado de Jaime I, se extendió por toda la Corona. Las reformas que se hicieron en el régimen interno de las aljamas para permitir a los judíos más pobres participar en la administración, no siempre fueron duraderas porque los ricos no escatimaron esfuerzos para expulsar a los representantes de los pobres de los cargos recientemente obtenidos. A pesar de que las familias de la aristocracia judía lograron recuperar una parte del poder que habían perdido, las clases más pobres, que seguían reivindicando sus quejas, no cejaron en su empeño de conseguir una participación en el gobierno comunitario. Su campaña corría pareja con la insatisfacción que su exclusión de los cargos de poder en los municipios, causaba a las clases clases inferiores de la sociedad circundante y no hay duda de que estaba inspirada por ella. La lucha de las clases baja y media judías, dio fruto a partir de principios del siglo 14 cuando la demanda de reformas constitucionales e institucionales se expandió rápidamente. Antes de que esas reformas se produjeran, las relaciones entre las familias más antiguas y adineradas que controlaban la quehilah por una parte y la nueva clase media que se estaba formando junto con los judíos más pobres por otra, era muy tensa y se caracterizaba por las sospechas y la desconfianza mutuas. Jaime II, sin cuya ayuda las clases inferiores nunca habrían podido conseguir ninguna de sus aspiraciones, prestó un apoyo moderado a sus reivindicaciones en una política que estaba dictada por una evaluación pragmática del descontento y de sus consecuencias potenciales.

53 ACA, Reg. 197, fos. 153v-154 [=Régné 2745 =BAER, Die Juden, doc. 146]; Reg. 239, fos. 18v19. [=BAER, Die Juden, doc. 164]; ACA, CR, Jaime II, Caja 134, no. 249 [=CINTA, The Jews in the Crown of Aragón, no. 468]; Caja 10, no. 249 [=CINTA, The Jews in the Crown of Aragón, no. 468]; Caja 10, no. 249 [=CINTA, The Jews in the Crown of Aragón, no. 1328]; Caja 2, no. 420; ACA, Reg. 229, fos. 260v-261, 274v-275 [=Régné 3432, 3436]; Reg. 211, fo. 337v [=Régné 3020].

54 ACA, CR, Jaime II, Caja 35, no. 4423 [=CINTA, The Jews in the Crown of Aragón, no. 153]; Caja 67, no. 8272 [=CINTA, The Jews in the Crown of Aragón, no. 344]; Caja, 80, no. 9731 [=CINTA, The Jews in the Crown of Aragón, no. 472]; Caja 39, no. 4847; Caja 99, no. 12364 [=CINTA, The Jews in the Crown of Aragón, no. 486]; Caja 134, no. 207 [=CINTA, The Jews in the Crown of Aragón, no. 416]; Caja 23, no. 2956; Caja 133, no. 66 [=CINTA, The Jews in the Crown of Aragón, no. 297]; Caja 134, nos. 206, 252 [=CINTA, The Jews in the Crown of Aragón, nos. 415, 471]. 
Entre la élite dirigente y las clases inferiores de Valencia, donde en una fecha tan tardía como 1297 todavía los dirigentes se elegían exclusivamente de las clases altas, reinaba un abierto antagonismo $0^{55}$. Tres años más tarde, durante el reparto de los impuestos reales y comunitarios entre los miembros, los representantes de las clases inferiores se quejaron al rey de que los ricos los oprimían y perjudicaban de distintas maneras. En respuesta, el rey decidió cambiar el sistema impositivo y la estructura del cuerpo encargado de la recaudación de los impuestos. A partir de entonces, la comisión ante la que cada contribuyente tenía que prestar juramento, incluiría un miembro de cada una de las tres clases. Estas tres personas serían elegidas por un concilium de doce miembros compuesto de cuatro representantes de cada clase. Ese mismo concilium o 'eza, junto con los berurim cuya cadencia terminaba, sería el encargado de nombrar a los nuevos berurim ${ }^{56}$. Algo más tarde, se decidió que los berurim salientes no podrían ser reelegidos en los tres años siguientes.

El viejo régimen, que se basaba sobre todo en privilegios que permitían a los oligarcas perpetuar su detentación del poder, no se abolió. La prohibición de elegir berurim a los familiares de los que ya lo eran, supuso asimismo un paso importante. La constitución de 1300 no terminó con las rivalidades y la agitación que reinaban entre los distintos grupos de la aljama de Valencia; pero, aunque fueron necesarias reiteradas intervenciones del monarca, el principio de que las tres clases tenían que estar representadas en todas las instituciones comunitarias, siguió constituyendo un rasgo permanente en la vida de la comunidad ${ }^{57}$.

Lo que sucedió en Valencia forma parte de una fase de agitación general y sentó un precedente que sería seguido por otras comunidades. En la vecina Murviedro el rey intentó poner fin a una larga serie de conflictos decidiendo que se formara un colegio electoral compuesto de seis miembros, dos de cada clase, que sería el encargado de elegir a todos los dirigentes cada dos años ${ }^{58}$. También en diversas comunidades aragonesas se produjeron cambios parecidos. En Huesca ${ }^{59}$, Barbastro ${ }^{60}$, Teruel ${ }^{61}$ y Calatayud ${ }^{62}$, la oposición de las clases más pobres terminó con las oligarquías diri-

55 ACA, Reg. 195, fo. 46 [=Régné 2661].

56 Según las clases inferiores «maiores judei et diviciis opulanti mediocres et minores in eis diversimode agravant et molestant»: ACA, Reg. 197, fos. 153v-154 [=Régné 27745 =BAER, Die Juden, doc. 146].

57 ACA, Reg. 214, fo. 23 [=Régné 3064]; Reg. 229, fo. 274 [=Régné 3434 =BAER, Die Juden, no. 188].

58 ACA, Reg. 230, fo. 59 [=Régné 3442].

59 ACA, Reg. 210, fo. 79 [=Régné 2976]; Reg. 225, fo. 280v [=Régné 3299]; R. DEL ARCO, «La aljama judaica de Huesca», Sefarad VII (1947), pp. 271-301.

60 ACA, Reg. 210, fos. 86-87 [=Régné 2977]; Reg. 229, fos. 177v-178 [=Régné 3404].

61 BAER, Die Juden, doc. 163.

62 Véase la carta enviada por los pobres de Calatayud al rey, ACA, CR, Jaime II, Caja 135, no. 411: «a la vuestra alteça claman merçe, senor, los judios de la mano menuda de Calatayud que sea vuestra merçe que.done... dar una comision general para don Domenge de Tarba que conozca de todos los aferes que son entre nos e los judios mayores porque toda verdat y pueda seyer sabida, senor, e vuestros derechos sean salvos e nos non seamos... enganosament".. 
gentes y se abolió su derecho a nombrar a sus propios sucesores en los cargos. La actitud positiva del rey, que estaba dictada por su realismo y pragmatismo políticos, posibilitó los cambios: en todos y cada uno de los casos, los representantes de las clases inferiores se dirigieron a él en demanda de ayuda. A pesar de las fluctuaciones, el logro más importante en este terreno de las clases media y baja, es decir, su derecho a compartir la administración comunitaria eligiendo representantes propios, se mantuvo en muchas comunidades. Pero quedaron vestigios de los privilegios de las familias ricas, y éstos supusieron una continua fuente de disensión en varias comunidades aragonesas ${ }^{63}$.

Las aljamas catalanas no quedaron inmunes al desasosiego social que caracterizó la vida de las comunidades valenciana y aragonesa. En el condado, los cambios más radicales en el sistema de gobierno comunitario se produjeron en 1308 en Lérida donde, en un primer momento, las clases alta y media llegaron a un acuerdo para repartirse entre ellas la administración de la qehilah, dejando fuera a la clase baja. Esta última intensificó su lucha y obtuvo de Jaime II que apoyara las reformas de 1315 que la incluían en el liderazgo comunitario ${ }^{64}$. La medida por la que oficiales que terminaban su cadencia no eran reelegibles en los tres años siguientes, que había sido adoptada para romper el monopolio de la clase alta, causó dificultades en esa comunidad como en todas las demás. Como cada clase estaba representada por el mismo número de personas fuera cual fuese su peso demográfico, a la clase alta no le resultaba fácil proporcionar tantos candidatos. Se intentó solucionar el problema respetando el marco del nuevo principio adoptado, pero el intento falló haciendo fracasar todo el sistema. Todos los esfuerzos por mantener la representación equitativa resultaron infructuosos. Pero la exclusión de las clases inferiores de los cuerpos gobernantes de la comunidad de Lérida después de haber participado en ellos, hay que verla como una excepción a la tendencia general ${ }^{65}$.

Durante el reinado de Jaime II, el régimen comunitario se estabilizó y permaneció casi intacto hasta la víspera de las matanzas de 1391. En muchos aspectos, el reinado de este monarca supuso un cambio decisivo en la historia de los judíos de la Corona de Aragón. Fue en este período cuando el centro de gravedad de la vida judía pasó de los cortesanos judíos a la aljama. El poder y los logros de esta última alcanzaron entonces su punto culminante. No es casualidad que el halajista más grande de la Corona de Aragón y, de hecho, de toda la península, Rabí Shelomo ben Adret, fuera también dirigente del judaísmo catalano-aragonés en la época de Jaime II. El rey mostró gran aprecio por Adret consultándole en diversas ocasiones y el rabino, por su parte, contribuyó en muy buena medida a la organización de la comunidad judía. La vida cultural y religiosa de los judíos de la Corona de Aragón, alcanzó en este reinado sus más altas cimas.

63 ACA, Reg. 227, fo. 191v [=Régné 3333]; Reg. 218, fos. 92v-93 [=Régné 3135 =BAER, Die Juden, doc. 174].

64 Yom Tov ASIBILI, Seelot u-Tešuvot (Responsa), ed. Y. Kapah, Jerusalem, 1959, no. 114; ACA, Reg. 212, fos. 30v-31 [=Régné 3026]; Reg. 216, fo. 83 [=Régné 3095].

65 ACA, Reg. 216, fos. 84v, 122v-123 [=Régné 3097, 3106]. 